\title{
The meaning of consolation as experienced by nurses in a home-care setting
}

\author{
Åsa Roxberg PhD, RN, RNT \\ Senior Lecturer, The School of Health Sciences and Social Work, Växjö University, Växjö, Sweden
}

Katie Eriksson PhD, RN

Professor, Head of Department of Caring Science, Åbo Academy, Vasa and Director of Nursing, Helsinki University Central Hospital, Helsinki, Finland

Arne Rehnsfeldt PhD, RNT

Associate Professor, Department of Social and Welfare Studies, Faculty of Health Sciences at Linköping University, Linköping, Sweden

Bengt Fridlund PhD, RNT

Professor, The School of Health Sciences and Social Work, Växjö University, Växjö, Sweden

Submitted for publication: 26 November 2006

Accepted for publication: 15 May 2007

\section{Correspondence:}

Åsa Roxberg

Senior Lecturer

The School of Health Sciences and Social

Work

Växjö University

Växjö

Sweden

Telephone: +46470708303

E-mail: asa.roxberg@swipnet.se
ROXBERG A, ERIKSSON K, REHNSFELDT A \& FRIDLUND B (2008) Journal of Clinical Nursing 17, 1079-1087

The meaning of consolation as experienced by nurses in a home-care setting Aims and objective. The aim of this study was to illuminate nurses' experiences of consolation and how these experiences relate to suffering and care.

Background. Consolation is commonly associated with the relief of suffering. The question of consolation in terms of its definition and relevance for care has, however, been a matter of discussion among nurse researchers. The question raised concerns about the nature of consolation, its place and its role in relation to care and the caring sciences.

Design. An explorative qualitative interview study with 12 participants, six registered and six enrolled nurses, was carried out in a home-care context.

Methods. A phenomenological-hermeneutic method inspired by the French philosopher Paul Ricoeur was used for the text analysis.

Results. Two main aspects of consolation appeared: 'the present consolation', which is flexible, sustaining and opening and 'the absent consolation', which conceals the suffering and is incapable of consoling. The result was interpreted from a philosophical-ethical perspective, based on the works of Levinas and Lögstrup.

Conclusions. Consolation appears as a complex phenomenon, both in terms of its existence and its absence consolation, constituting a caring and non-caring consolation. A caring consolation entails meeting the other as different and being present in a way that gives the other space to be the one he or she really is. It requires acceptance, accepting the sufferer and his/her way of suffering as unique. 
Relevance to clinical practice. The clinical nurse is involved in complex care situations, which entails both reflecting upon and using intuition when consoling. A caring consolation is a contradictory phenomenon that requires a nurse to be capable of both reflecting upon and acting intuitively on the unique suffering of the other.

Key words: caring, consolation, ethics, nurses, nursing, Phenomenological Hermeneutics

\section{Introduction}

Consolation and comfort are commonly associated with the relief of suffering and have been part of modern care from the days of Florence Nightingale up to the present (Nightingale 1952, Morse 1999). However, the question of consolation/comfort and its relevance for care has been a matter of discussion among nurse researchers. According to Morse (1999), comfort has always been in the heart of nursing' (p. 394) but not much has been done to investigate it. Morse (1992) argues that the concept of caring is inadequate. The ultimate purpose of caring is, instead, to promote comfort rather than care. Kolcaba et al. (2006) add that the use of a comfort theory provides a coherent and consistent pattern for enhancing care. On the other hand, Tutton and Seers (2003) maintain that there is no evidence of this in the literature and that the concept of comfort is still not clearly defined (Siefert 2002). Seemingly, there is some disagreement about the evidence of comfort related to care and this raises questions about the nature of comfort, its place and its role in relation to care and the caring sciences (cf. McIlveen \& Morse 1995, Kolcaba \& Fisher 1996, Kolcaba \& Steiner 2000).

The two words, comfort and consolation, are closely related terms with similar meanings. Consolation is linked with the act of mediating relief to the mind under affliction and indicates a source of that relief (Oxford Advanced Learner's Dictionary 2005). Consolation is chosen in this study because this word better communicate the act of mediating relief. Suffering is seen as a threat to a person's lifeworld and experience of wholeness. Trying to regain the lost wholeness is part of the experience of suffering as well as of health (Gadamer 1996, Eriksson 2002, Dahlberg et al. 2003). Care is seen as the basic motive for doing another person good (Eriksson 2002, Dahlberg et al. 2003) and is guided by the sufferer and his/her way of suffering (Morse 2001).

In the light of the aforementioned disagreement it is thus relevant to investigate the phenomenon further and its relation to suffering and care. For this reason, the aim of the study was to illuminate nurses' experiences of consolation and how these experiences are related to suffering and care.

\section{Literature review}

Previous research shows that the concept of consolation is individual (Siefert 2002), holistic (Kolcaba 1992, 1994) and gender specific. Women are more likely to seek religious consolation than men, who seek consolation for wider spectra of problems (Ferraro \& Kelley-Moore 2000). Comfort is defined as a state of well-being (Morse 1992, Kolcaba \& Steiner 2000) and is experienced in a close fellowship, a presence that is characterised by communion (cf. Rasmussen 1999, Söderberg 1999, Rasmussen et al. 2000, Sundin et al. 2000, 2002, Norberg 2001, Norberg et al. 2001, Talseth et al. 2001, 2003, Sundin \& Jansson 2003). Consolation is described as a 'calm liturgy of caring', created in an atmosphere of openness and to be in a wordless communication, a 'caring communion' (Sundin et al. 2000, 2002). To be embraced by memories was experienced as consolation by the very old persons and enabled them to feel whole (Santamäki Fischer 2007). Patients felt that God was listening to them and was answering their prayers when they sought comfort (Hawley \& Irurita 1998). Patients in an intensive care unit also need a human touch and consolation, which can transcend technology (Nussbaum 2003). Attitudes to spiritual care among nursing staff in a Swedish oncology unit show that the degree of comfort correlates positively with the self-estimated ability to perform and the frequency of giving spiritual care as well as to the extent to which one considers that nurses should engage in spiritual care (Lundmark 2006). Consolation can be likened to coming home and the feeling of being at home while suffering can be likened with the opposite, that of not feeling as although one is at home (Rasmussen et al. 2000, Norberg et al. 2001).

Consolation is changing focus from the suffering to something in between, a communion (Rasmussen 1999, Rasmussen et al. 2000, Talseth et al. 2001). The in-between might also be understood as an experience of time and space to be able to suffer and to get a consoling interval from the suffering (Öhlén \& Holm 2006). Consolation is also opening the way for hope (Talseth et al. 2001) and a few studies have shown that consolation also concerns health (Alfredson et al. 1995, Pejlert et al. 1999, Malinowsky \& Leeseberg Stamler 
2002). In summary, research that focuses on consolation is dealing with a set of interrelated dimensions. These dimensions reveal that consolation seems to inhabit a profound quality of caring as an art. Outstanding qualities are a tacit sensitivity to the suffering of the other and an act of consolation that entails more of being with than doing for. However, the literature also reveals ambiguity concerning the use of consolation and its relevance for care. Altogether this points towards a need for clarification of the relation between consolation, suffering and care.

\section{Methods}

\section{Design and setting}

An explorative, qualitative study was carried out in a homecare setting. The motive for this choice was based on an assumption that the relationship between a nurse and a patient might be closer and consolation more evident in this type of setting comparison with a hospital setting. The major responsibility and resources for care of older people was in 1992 transferred to the municipalities in Sweden (Johansson 1997). Thus, the majority of the patients in this study were older, living in their own homes with a wide range of care needs, i.e., from minor needs to needs of terminal care. The study was conducted in southern Sweden, in both urban and rural areas.

\section{Informants}

Six registered and six enrolled nurses were selected with the help of the senior nursing officer for the unit, who also distributed written information (informed consent) about the study to the presumptive informants. The inclusion criteria were:

1 At least three years of work experience in the actual setting;

2 Experienced and competent within their profession;

3 Interested in sharing and reflecting upon experiences of consolation;

4 Swedish-speaking.

The first and second criteria were based on the assumption that work experience of at least three years makes nurses well acquainted with their work and with their patients. Relationships over a long time are common in home-care settings and were assumed to increase the ability to mediate consolation. The third criterion was set because of the presumption that a shared interest in the research phenomenon is of vital importance for making a good interview. The fourth criterion was set because of the necessity to have a good command of the language to participate in the interview. All informants agreed on being interviewed and to the interviews being audio-taped. The participants in the study were all women, 26-62 years old and with a professional experience ranging from 7-38 years. The main reason for this overrepresentation of women is that they are over-represented in the care services (Statistics Sweden 2004). The principles of research ethics were adhered to which meant respecting the informant's liberty to abstain from participating in the study and that the informant was also free to withdraw his/her consent to participate at any time. The study was approved by the manager of the home-help services and by the Ethics Committee (LU 193-00), Lund University, Sweden.

\section{Interviews}

Narrative interviews were conducted, i.e. interviews in which the informants, without being interrupted, were free to talk and reflect over themes central to the study. The themes were formulated from the preunderstanding and from the result of the literature review. The themes were: what is consolation and what is evoked by consolation? What are the hindrances for mediating/receiving consolation? What makes it easier for consolation to be mediated/received? What is suffering and what is evoked by suffering? Is there any connection between consolation and spirituality/faith? Further clarifying questions were asked during the interview to understand the narrative and questions such as 'What did you feel then?' were also asked. During the first interviews the informants related without being asked experiences of home and what home meant to the patients as well as to themselves. Another theme about the meaning of home and its relation to consolation was thus added. The interviews lasted for 1-1.5 hours and were conducted in a secluded area at the informant's place of work. The first author carried out all interviews as well as transcribed the interviews verbatim.

\section{Data analysis}

Phenomenology and hermeneutics formed the basis for the methodological approach. A phenomenological-hermeneutic method, inspired by the French philosopher Paul Ricoeur and developed by Lindseth and Norberg (2004), was used for the text analysis. The reason for this preference was that Ricoeur (1981) claims that phenomenology is the presupposition of hermeneutics and that phenomenology cannot constitute itself without a hermeneutical presupposition. The focus of the text analysis was thus on the meaning of lived experience as expressed in the text. Ricoeur (1976) also emphasises that metaphors contain a surplus of meaning and, therefore, say something new about something already known. 
The analysis was performed in several steps, although not separated from each other. The first step included a naïve reading to grasp the first meaning of the text as a whole. The next step, the structural analysis, was the methodical instance of interpretation. A structural analysis gives, according to Ricoeur (1975), more meaning to the intrigue than the first naïve reading. The world of the text is seen as being closed and it is what the text says and not what it talks about, which at this time is in focus (Ricoeur 1993). A thematic form of structural analysis was performed. A theme is a kind of thread, a thread of meaning, which is expressed both in the parts (subthemes) and in the wholes (themes). The text was divided into smaller units, i.e., meaning units. A meaning unit can be a whole paragraph, a sentence or part of a sentence, i.e., a piece of any length that illustrates the meaning of the actual unit. The meaning units were also reflected on in relation to the naïve understanding as well as the preunderstanding. Meaning units were then abstracted, which means that they were brought together in terms of similarities and differences to form subthemes and themes (see Table 1). The final step was a comprehensive understanding of the result, i.e. of the themes and subthemes, including the naïve and structural analysis of the text. This step included an interpretation of the result to acquire a deeper understanding of the phenomenon. This interpretation can be done in light of relevant literature, such as an appropriate theory. For this study the ethics of Levinas (1985) and of Lögstrup (1965) were chosen.

Table 1 Examples of the structural analysis of consolation

\begin{tabular}{|c|c|c|c|}
\hline Meaning units & Meaning code & Sub themes & Themes \\
\hline $\begin{array}{l}\text { No, one is not walking around } \\
\text { thinking of consoling, it is just } \\
\text { something that happens'//'to just be } \\
\text { present...consolation being present }\end{array}$ & Immediacy, spontaneous & The flexible consolation & 'The present consolation' \\
\hline $\begin{array}{l}\text { Managed to console a little bit } \\
\text { more//then one can feel that one has } \\
\text { succeeded a little bit more or one can } \\
\text { feel that one has succeeded to console } \\
\text { a little bit more }\end{array}$ & Potential & The opening consolation & \\
\hline $\begin{array}{l}\text { It [home] is a kind of sanctuary, where } \\
\text { there are no demands as outside the } \\
\text { home... it might have [to do with } \\
\text { consolation]. }\end{array}$ & Retreat & The sustaining consolation & \\
\hline $\begin{array}{l}\text { Being a preoccupied person...it is just } \\
\text { me who counts, me as staff member, } \\
\text { it is only what I think that counts and } \\
\text { then I cannot walk in and console } \\
\text { someone }\end{array}$ & Self-centred & The concealing consolation & 'The absent consolation' \\
\hline $\begin{array}{l}\text { So he [the pastor] went in and greeted } \\
\text { the lady, dressed in black clothes, } \\
\text { big, stout and she was nearly } \\
\text { curtsying in bed...it was a wrong } \\
\text { type of consolation, there one could } \\
\text { see how wrong consolation can be } \\
\text { too }\end{array}$ & Reducing & & \\
\hline $\begin{array}{l}\text { If you are not feeling emotionally well, } \\
\text { I cannot see how you can be a good } \\
\text { consoler either }\end{array}$ & Estranged from oneself & The incapable consolation & \\
\hline $\begin{array}{l}\text { There are some who do not want to be } \\
\text { consoled either, they want to } \\
\text { have...go into their own world, in } \\
\text { their grief or what has happened }\end{array}$ & Estranged from consolation & & \\
\hline $\begin{array}{l}\text { Being a preoccupied person...it is just } \\
\text { me who counts, me as staff member, } \\
\text { it is only what I think that counts and } \\
\text { then I cannot walk in and console } \\
\text { someone }\end{array}$ & & & \\
\hline
\end{tabular}




\section{Findings}

\section{The naïve reading}

The nurses often spoke about the impact of a good and caring relation and that consolation was mediated in a close relation. Mutual openness was described as an important factor for mediating and receiving consolation. This mutual openness created a sense of presence in the act of consoling. The text also described what was termed as a consolation that appeared to entail a distance to the sufferer and the experience of suffering. The text was rich in contrasts as well as metaphors, one of which contained a description of consolation as a stone that in a painful process comes loose. This metaphor seemed to indicate that the relationship between consolation and suffering is not a one-sided but complex phenomenon.

\section{The structural analysis}

The result of the structural analysis, considering the preunderstanding and the naïve reading, revealed what appeared as two opposite aspects of the phenomenon consolation. Two main themes were abstracted: 'the present consolation' and 'the absent consolation'. The themes should be seen as contrasting qualities of consolation, one that is felt to exist, i.e. is present and one that is distinguishable by its absence, not being present.

\section{The present consolation}

The structural analysis revealed three dimensions of a 'present consolation', characterised as being flexible, opening and sustaining.

\section{The flexible consolation}

The nurses described a consolation that met the sufferer in his/her suffering, '...to just be present...consolation being present...' (Informant A). The flexible consolation did not follow general principles or patterns. It was a consolation that could not be taught nor learned, but was emerging spontaneously when encountering the suffering of the other. It meant a consolation that engaged in the suffering of the other and was 'spoken from the heart'. This consolation could, therefore, not be planned as a planned consolation became wrong: 'no, one is not walking around thinking of consoling, it is just something that happens (Informant F). This consolation also adjusted to the suffering and the sufferer by being flexible in terms of 'kind of consolation' and 'ways of consoling'. What was regarded as suffering differed from one individual to the other and the same was true for consolation: 'It differs, I mean you console in different situations, it depends on what has happened//...when you see that it is the right time [to console]... if the other is able to receive any consolation today' (Informant I).

\section{The opening consolation}

A consolation that was capable of opening up the suffering was also described. The metaphor 'to open a door' was frequently used. The one to open was the one in need of consolation, but the nurses themselves also created openings into the suffering: 'So there I felt that I opened something' (Informant L). To show one's own vulnerability to the patient was also described as a 'door-opener' for consolation. The nurses reflected about the suffering itself working as a 'dooropener' that made it easier to get closer to patients who were suffering a lot. Another reflection was that suffering created a need for the other in a way which lead to a real encounter: 'I felt that some who (the patients) were in a bad condition, suffering a great deal, some of these patients you came much closer to then' (Informant J). Consolation was also described as a potential, meaning it was always possible to console and that all humans were in need of consolation. Another aspect of the consolation was experienced when the nurses 'managed to console a little bit more//then one can feel that one has succeeded a little bit more or one can feel that one has succeeded to console a little bit more' (Informant H). In the nurses' narratives a consolation appeared that included both giving and receiving, i.e. when the nurses consoled, they experienced consolation themselves. This consolation was multiplying itself through the act of consolation. The phenomenon seemed to be a kind of mutual influence which opened both the sufferer and the nurse for consolation: 'It was a very pleasant experience for me to hear him talking about his life. It was a kind of consolation also for me that he told me about his life and how the situation was now and how it had been before' (Informant C). Consolation was also described as making a narrow perspective wider. One nurse illustrated this by using a metaphor of a cone. Looking through the wide opening gives a very narrow perspective. On the other hand, using the narrow opening gives a wider perspective, making it possible to see the whole of the human being and what is around.

\section{The sustaining consolation}

A consolation that protected the sufferer from being overwhelmed by the suffering, was also described. This was done 
by 'portioning out' the suffering, which in turn sustained the sufferer's emotional balance. It was described, metaphorically, as a balloon, a balloon which should be gradually emptied: 'Yes, one should not even have to puncture the balloon because one should be able to gradually let the air out all the time//Regularly so that there are not so many ups and downs in emotional life' (Informant K). The nurses were also practising a consolation that sustained their patients by letting them suffer. One nurse described how she let the patient be undisturbed, to let the suffering be suffered until the pain had passed: 'Then they [patients in psychiatric care] start to walk around and start to breathe, I just let them be by themselves for a while' (Informant B).

An experience of the well-known, of everyday familiarity was described as consolation for older people. This experience was sustaining as it made it possible to recognize oneself in the positive memories of the past, to anchor the present to the past: 'things that have been well-known for a long time...that is well-known, I think it is a consolation, being able to recognize these things, I think this is consolation really' (Informant L). The nurses reflected on what the home meant, for their patients as well as what it meant for themselves. In the nurses' perspective home was for their older patients connected with positive memories of the past, with their childhood, adult and family life and with the present life as an older person. Home was, therefore, described as representing the whole life-world of older people, as captured in a little 'bag' that might include consolation. The nurses' reflections on what the relation between home and consolation meant also included home as a sanctuary. This was described as a kind of place that allows one to be oneself, without experiencing the demands of the world outside: 'I think it [the home] represents everything really, meals, happy moments and sad moments, it is all there in a little bag...//...it is a kind of sanctuary, where there are no demands as outside the home...it might have [to do with consolation]. I think that there is security and understanding in the home or should be, it is not self-evident that there is but there should be' (Informant $\mathrm{H}$ ).

\section{The absent consolation}

The absence of consolation appeared as a concealing of the suffering and an incapability to console.

\section{The concealing consolation}

Firstly, this kind of consolation emerged when the nurses avoided the sufferer and his/her suffering. The reasons for avoiding were generally that the nurses were preoccupied with their own thoughts. This preoccupation made it impossible to focus on the other and thus hindered consolation: 'Being a preoccupied person...it is just me who counts, me as staff member, it is only what I think that counts and then I cannot walk in and console someone' (Informant A). Some of the aspects of being preoccupied were expressed in terms of 'taking too much of one's own time to console' and that the nurses' own problems were a hindrance for consolation. It was described as an experience of internal stress and a desire not to show the stress, a longing to be alone to suffer one's suffering. Secondly, the concealing aspect of this kind of consolation was described as acting and caring in a particular way. It was expressed as being professional, which meant not crying, not showing too much compassion but to be strong to show the patient, 'this is how it [in reality] is'. Another example was when the suffering was symbolically removed, i.e. when it was prevented from being expressed. By expressing the suffering instead of letting the person express it him/ herself it was concealed from being suffered. By doing so the nurse revealed that he/she was not prepared to receive the suffering other:...' by putting words in the mouth of people who are sad' (Informant I). Thirdly, a concealing consolation was described as a kind of reduction of the suffering and the sufferer. The interviewee exemplified this by describing a pastor and a nurse. The nurse was consoling in a way as if she had consoled a child while just the appearance of the pastor seemed to provoke a kind of reverence. These were examples of how wrong consolation can be: 'So he went in and greeted the lady, dressed in black clothes, big, stout and she was nearly curtsying in bed...it was a wrong type of consolation, there one could see how wrong consolation can be too' (Informant A).

\section{The incapable consolation}

The difficulty in consoling someone that the person does not know very well or does not have a relation to was also described. The attempts to console then easily turned into a superficial consolation and the act of consolation as 'not being done in the real way'. When there was no experienced relation between the consoler and the person in need of consolation a feeling of estrangement appeared: 'Because I think it is difficult to console somebody you do not know, well you can do it a little, perhaps superficially but not really, not in a real way (Informant I). It was also difficult to console if the nurse was not emotionally balanced: '...If you are not feeling emotionally well, I can not see how you can be a good consoler either' (Informant A). The nurses thought that consolation was undesirable in a suffering that the individual wants to remain in or in a consolation that he/she does not 
want. They also emphasised that the sufferer might not need the actual consolation and/or that the sufferer rejected being consoled by the actual carer:... 'there are some who do not want to be consoled either, they want to have...go into their own world, in their grief or what has happened' (Informant G)//...'so long as the door is closed you are not getting much further [with consoling], at least not for the time being' (Informant K). Consolation was unsuccessful when it did not manage to console according to the expectations of the sufferer or the consoler him/herself. According to the nurses the main reason was the burden of work. This created an incapacity to be able to respond to the other's suffering and to be able to console, as the nurses were bound by time limitations that were not sufficient to meet the needs of everyone and everything: 'At the same time you feel that you are pulled in all directions that you can't be present' (Informant L).

\section{Comprehensive understanding and reflections}

The result of the naïve reading and the structural analysis points towards a consolation, which captures a contradiction both in terms of its existence and its absence. 'The present consolation' is flexible to the suffering, opens up the suffering and sustains the sufferer. The concealing and incapable consolation, on the contrary, is not where the sufferer is. To view 'the present consolation' through its absence might contribute to the ongoing research of what consolation is and what it is not.

'The present consolation' can be understood as a care based on mercy, sacrifice and love for the suffering other. Mercy and love are the presuppositions of a care that has its starting point in the other and his/her suffering (Eriksson 1995, Helin \& Lindström 2003). Mercy and love are also characterised as spontaneous life utterances (Lögstrup (1965). In light of this study, the spontaneous life utterances may well be understood as a kind of peaceful relief from the suffering, created when these life utterances are mediated. The concealing and incapable consolation fails to attend to the very reason for care, namely the sufferer. According to Lögstrup (1965) 'the absent consolation' may be understood as a perversion of the spontaneous life utterances. Instead of being creative and creating, the perverted life utterances draw the attention from the sufferer to the consoler.

The responsibility for the other is a responsibility even for that which does not concern 'me'. When the nurse declares to the sufferer: 'Here I am' it means, 'Here I am as responsible for you'. This closeness is, however, not only a closeness in the physical sense or closeness due to kinship. Instead the other comes closer because the nurse is feeling responsible for him/her (Levinas 1985). When the nurse tries to view the sufferer's experience of the suffering as similar to the nurse's own experience, i.e., is looking for similarities between his/ her own world in the world of the other, a feeling of being distant appears. This estrangement can be understood in different ways. When it comes to consolation the feeling of estrangement seems to point to an important aspect of a caring consolation. On a superficial level of understanding, all patients are strangers. In most cases, no deeper relation is created in the initial phase between the nurse and the patient, although, in a deeper sense, to meet the other as another seems to indicate a vital aspect of what consolation is and what it is not. To meet the other as another is to create space to allow the person to be who he/she really is. This space includes the possibility to be able to suffer in one's own way. It seems that the ability to meet the other as a different person, in the long run, has to do with the consoler. When the nurse has a kind of inner security he/she dares to reach out towards the other as another and invites him/her into a relation where he/she is allowed to be the one he/she really is. A nurse with this kind of trust also dares to encounter the sufferer spontaneously, i.e., allowing him/herself to be carried along in the flow when mediating the spontaneous life utterances (Lögstrup 1965).

This study shows that consolation was viewed as a feeling of being at home, like being in a sanctuary. The home was seen as a place that promoted the feeling of being secure and protected from the demands of the world outside. This metaphor seems to capture a vital meaning of 'the present consolation'. Consolation is experienced when met in a non-judging and accepting way (Talseth et al. 2001) and consolation makes us available to others (Söderberg 1999). In the light of this study, a caring consolation means to promote a feeling of being accepted and secure. It entails assisting the patient in finding a kind of inner space where it is possible to rest in or from the suffering. The findings of this study and previous research point towards an experience of being welcomed, protected and relaxed within the presence of consolation.

Patients suffering from care are described by Eriksson (1994) and Dahlberg et al. (2003). This study is in line with what might be likened to nurses' suffering from care, i.e. from a work burden that created an incapacity to be able to respond to the other's suffering and to be able to console. The cause of this suffering is probably found at another level of the care hierarchy but it could also be seen as a 'stress of conscience'. Nurses report that they have to deaden their conscience to be able to work in health care (Glasberg et al. 2007). This could also be understood as nurses' deadening their ability to mediate as well as experience consolation. The 
findings of this study reveal that mediating consolation opens the mediator to experience consolation. Hence, one way of reducing the risk of burnout caused by caring is to open up for being consoled when consoling. According to Lynch (2002) this can be seen as a kind of being in the doing, like a consoling sanctuary in an environment filled with demands (cf. Öhlén \& Holm 2006).

\section{Methodological considerations}

The methodological approach highlighted the meaning of nurses' experiences of consoling in the midst of real life situations. The phenomenological-hermeneutic approach thus seems applicable as it has been able to show how nurses in these complex care situations reflect upon and mediate consolation. Trustworthiness includes the question of transferability, to what extent the findings can be transferred to other contexts (Polit 2006). The extent of transferability seems to be high as the results, although dealing with an abstract phenomenon, are applicable to caring situations in different environments. Therefore, the findings give the impression of being less related to context than to what they mean in a more general sense. The fact that no men were represented in the study may have influenced the result. It seems reasonable to assume that a male aspect of consolation might in some aspects differ from a female aspect (cf. Ferraro $\&$ Kelley-Moore 2000). Credibility was achieved by the maintenance of an open dialogue between the researchers during the research process. Credibility was also maintained by being thorough in every step of the text analysis, including the considering and arguing for and against different interpretations. There is however not one correct and universal interpretation, only the most probable amongst several interpretations (Ricoeur 1976). It is thus up to the reader to validate how well the findings correspond with the researchers' interpretations.

\section{Conclusions and implications}

The meaning of consolation as experienced by nurses in a home-care setting show two main dimensions, 'the present consolation' and 'the absent consolation'. Firstly, the difference is to be present or not to be present to the sufferer in his/ her suffering. Secondly, the difference is also that 'the present consolation' has a different approach when encountering the sufferer and his/her suffering. To be present means to have a kind of reflective mind that takes into account that the suffering of the other might differ from the nurse's own view of what suffering should be like and how it should be suffered. Thirdly, a 'present consolation' appears as equivalent to a caring consolation as well as an absence of consolation appears as equivalent to a non-caring consolation. Finally, to practice a 'present consolation' requires a nurse with a reflective mind. On the other hand it also requires a nurse who dares to act in accordance with his/her intuition of how to console in the actual encounter with the sufferer. A suggestion for further research is to investigate what consolation means to persons who have rich experiences of being consoled. This could further generate a profound understanding of what consolation is and what it is not.

\section{Acknowledgement}

This study was supported by grants from: the Swedish Order of St John, the South of Sweden Nursing Home and the Swedish Society of Nursing.

\section{Contributions}

Study design: ÅR, KE, AR, BF; data collection and analysis: ÅR, AR, KE and manuscript preparation: BF and ÅR.

\section{References}

Alfredson E, Wiren B \& Lützén K (1995) 'Consolation ', a wave of benevolence and well-being'. A qualitative study of elderlies' experiences of consolation. Nursing Science and Research in the Nordic Countries 2, 34-39 (in Swedish).

Dahlberg K, Segesten K, Nyström M, Suserud B-O \& Fagerberg I (2003) To Understand Caring Science. Studentlitteratur, Lund (in Swedish).

Eriksson K (1994) The Suffering Human Being. Department of Caring Science, Åbo Academy, Vasa (in Swedish).

Eriksson K (1995) Towards a caritative caring ethics. In Towards a Caritative Caring Ethics (Eriksson K ed). Department of Caring Science, Åbo Academy, Vasa (in Swedish), pp. 9-39.

Eriksson K (2002) Caring science in a new key. Nursing Science Quarterly 15, 61-65.

Ferraro KF \& Kelley-Moore JA (2000) Religious consolation among men and women: do health problems spur seeking? Journal for the Scientific Study of Religion 39, 220-234.

Gadamer H-G (1996) The Enigma of Health: The Art of Healing in a Scientific Age. Polity Press, Cambridge.

Glasberg AL, Eriksson S \& Norberg A (2007) Burnout and 'stress of conscience' among health personnel. Journal of Advanced Nursing 57, 392-403.

Hawley G \& Irurita V (1998) Seeking comfort through prayer. International Journal of Nursing Practice 4, 9-18.

Helin K \& Lindström UA (2003) Sacrifice: an ethical dimension of caring that makes suffering meaningful. Nursing Ethics 10, 414427.

Johansson L (1997) Decentralisation From Acute to Home Care Settings in Sweden. National Board of Health and Welfare, Socialstyrelsen, Stockholm. 
Kolcaba KY (1992) Holistic comfort: operationalizing the construct as a nurse-sensitive outcome. Advances in Nursing Science 15, $1-10$.

Kolcaba KY (1994) A theory of holistic comfort for nursing. Journal of Advanced Nursing 19, 1178-1184.

Kolcaba KY \& Fisher EM (1996) A holistic perspective on comfort care as an advance directive. Critical Care Nursing Quarterly 18, 66-76.

Kolcaba K \& Steiner R (2000) Empirical evidence for the nature of holistic comfort. Journal of Holistic Nursing 18, 46-62.

Kolcaba K, Tilton C \& Drouin C (2006) Comfort theory. A unifying framework to enhance the practice environment. The Journal of Nursing Administration 36, 538-544.

Levinas E (1985) Ethics and Infinity. Conversations with Philippe Nemo. Duquesne University Press, Pittsburgh.

Lindseth A \& Norberg A (2004) A phenomenological hermeneutical method for researching lived experience. Scandinavian Journal of Caring Sciences 18, 145-153.

Lögstrup KE (1965) The Ethical Demand. Fortress Press, Philadelphia, PA.

Lundmark M (2006) Attitudes to spiritual care among nursing staff in a Swedish oncology clinic. Journal of Clinical Nursing 15, 863-874.

Lynch B (2002) Care for the caregiver. Midwifery 18, 178-187.

Malinnowsky A \& Leeseberg Stamler L (2002) Comfort: exploration of the concept in nursing. Journal of Advanced Nursing 39, 599606.

Mcllveen KH \& Morse JM (1995) The role of comfort in nursing care: 1900-1980. Clinical Nursing Research 4, 127-148.

Morse JM (1992) Comfort: the refocusing of nursing care. Clinical Nursing Research 1, 91-106.

Morse JM (1999) Qualitative methods: the state of the art. Qualitative Health Research 9, 393-406.

Morse JM (2000) On comfort and comforting. American Journal of Nursing 100, 34-38.

Morse JM (2001) Toward a praxis theory of suffering. Advances in Nursing Science 24, 47-59.

Nightingale F (1952) Notes on Nursing, 4th edn. Herald Duckworth \& Co. Ltd, London.

Norberg A (2001) Consoling care for people with Alzheimer's disease or another dementia in the advanced stage. Alzheimer's Care Quarterly 2, 46-52.

Norberg A, Bergsten M \& Lundman B (2001) A model of consolation. Nursing Ethics 8, 544-554.

Nussbaum G (2003) Spirituality in critical care. Patient comfort and satisfaction. Critical Care Nursing Quarterly 26, 214-220.

Öhlén J \& Holm A-C (2006) Transforming desolation into consolation: being a mother with life-threatening breast cancer. Health Care for Women International 27, 18-44.

Oxford Advanced Learner's Dictionary (2005) Oxford Advanced Learner's Dictionary (7th ed.). Oxford University Press, Oxford.
Pejlert A, Norberg A \& Asplund K (1999) Towards recovery: living in a home-like setting after the move from a hospital ward. Journal of Clinical Nursing 8, 663-674.

Polit DF (2006) Essentials of Nursing Research: Methods, Appraisal and Utilization, 6th edn. Lippincott Williams \& Wilkins, Philadelphia, PA.

Rasmussen BH (1999) Inpursuit of a Meaningful Living Amidst Dying. Nursing Practice in a Hospice. Medical Dissertation, New Series No 592, Umeå University, Umeå.

Rasmussen BH, Jansson L \& Norberg A (2000) Striving for becoming at-home in the midst of dying. American Journal of Hospice \& Palliative Care 17, 31-43.

Ricoeur P (1975) Biblical hermeneutics. Semeia 4, 30-148.

Ricoeur P (1976) Interpretation Theory: Discourse and the Surplus of Meaning. Christian University Press, Fort Worth, Texas.

Ricoeur P (1981) Hermeneutics and the human sciences. In Essays on Language, Action and Interpretation (Thompson JB ed). Cambridge University Press, Cambridge.

Ricoeur P (1993) From text to action. In An Anthology on Hermeneutics, 4th edn (Brutus Ö ed). Brutus Östlings Bokförlag Symposium AB, Stockholm (in Swedish).

Santamäki Fischer R (2007) Living in consolation while growing very old. Medical Dissertation, New Series No 1087, Umeå University, Umeå, Sweden.

Siefert ML (2002) Concept analysis of comfort. Nursing Forum 37, $16-23$.

Söderberg A (1999) The practical wisdom of enrolled nurses, registered nurses and physicians in situations of ethical difficulty in intensive care. Medical Dissertation, New Series No 603, Umeå University, Umeå, Sweden.

Statistics Sweden (2004) Labour Market Statistics. Statistics, Örebro, Sweden.

Sundin K \& Jansson L (2003) 'Understanding and being understood' as a creative caring phenomenon-in care of patients with stroke and aphasia. Journal of Clinical Nursing 12, 107-116.

Sundin K, Jansson L \& Norberg A (2000) Communicating with people with stroke and aphasia: understanding through sensation without words. Journal of Clinical Nursing 9, 481-488.

Sundin K, Jansson L \& Norberg A (2002) Understanding between care providers and patients with stroke and aphasia: a phenomenological hermeneutic inquiry. Nursing Inquiry 9, 93-103.

Talseth A-G, Gilje F \& Norberg A (2001) Being met - a passageway to hope for relatives of patients at risk of committing suicide: a phenomenological hermeneutic study. Archives of Psychiatric Nursing 6, 249-256.

Talseth A-G, Gilje F \& Norberg A (2003) Struggling to become ready for consolation: experiences of suicidal patients. Nursing Ethics 10, 614-623.

Tutton E \& Seers K (2003) An exploration of the concept of comfort. Journal of Clinical Nursing 12, 689-696. 